\title{
Neutrophils and Immunity: From Bactericidal Action to Being Conquered
}

\author{
Tie-Shan Teng, ${ }^{1}$ Ai-ling Ji, ${ }^{1}$ Xin-Ying Ji, ${ }^{1,2}$ and Yan-Zhang $\mathrm{Li}^{1}$ \\ ${ }^{1}$ School of Medical Sciences, College of Medicine, Henan University, Kaifeng, Henan 475004, China \\ ${ }^{2}$ Nanshi Hospital, Henan University College of Medicine, Nanyang, Henan 453003, China \\ Correspondence should be addressed to Xin-Ying Ji; xinying_ji@henu.edu.cn
}

Received 15 December 2016; Accepted 29 January 2017; Published 19 February 2017

Academic Editor: Clifford Lowell

Copyright (c) 2017 Tie-Shan Teng et al. This is an open access article distributed under the Creative Commons Attribution License, which permits unrestricted use, distribution, and reproduction in any medium, provided the original work is properly cited.

\begin{abstract}
The neutrophil is the major phagocyte and the final effector cell of the innate immunity, with a primary role in the clearance of extracellular pathogens. Using the broad array of cytokines, extracellular traps, and effector molecules as the humoral arm, neutrophils play a crucial role in the host defense against pathogen infections. On the other hand, the pathogen has the capacity to overcome neutrophil-mediated host defense to establish infection causing human disease. Pathogens, such as $S$. aureus, have the potential to thwart neutrophil chemotaxis and phagocytosis and thereby succeed in evading killing by neutrophils. Furthermore, $S$. aureus surviving within neutrophils promotes neutrophil cytolysis, resulting in the release of host-derived molecules that promote local inflammation. Here, we provide a detailed overview of the mechanisms by which neutrophils kill the extracellular pathogens and how pathogens evade neutrophils degradation. This review will provide insights that might be useful for the development of novel therapies against infections caused by antibiotic resistant pathogens.
\end{abstract}

\section{Introduction}

The immune system protects the body from microbes that invade and harm the host. In humans roughly 100 billion neutrophils enter and leave circulating blood every day [1] and constitute the dominant leukocyte population in the circulation, mediate the earliest innate immune responses to infection, and play a pivotal role in the resolution of microbial infections. Neutropenia, an acquired or inherited neutropenia, and neutrophil malfunction result in recurrent, lifethreatening infections with bacteria [2]

Neutrophils originate and mature in the bone marrow and are subsequently released into the peripheral vasculature. After a pathogen has breached the epithelial barriers, neutrophils are the first innate immune cells that are rapidly recruited from the bloodstream to sites of infection. Pathogens entry and replication in host tissues lead to the release of exogenous products, such as formyl peptides, lipoproteins, or peptidoglycan. Moreover, the invasive pathogen can also damage body tissues that produce inflammatory signals, for example, chemoattractants and cytokines [3]. These pathogenic products and inflammatory signals are detected by neutrophils via Toll-like receptors (TLRs), G protein-coupled receptors (GPCR), and cognate immune receptors. By sensing the receptor signal, neutrophils will respond to these stimuli, extravasate from blood vessels, and migrate towards the site of infection to phagocytose pathogens. This multistep process encompasses rolling adhesion of neutrophils on endothelial cells, firm adhesion of neutrophils, extravasation through the endothelium, chemotactic migration, and subsequent killing of invading bacterial pathogens. Following migration to the site of infection and phagocytosis, neutrophils have a repertoire of antimicrobial arsenal at their disposal to fulfil this function [4]. Neutrophils utilize a combination of NADPH oxidase-derived reactive oxygen species (ROS), cytotoxic granule components, antimicrobial peptides, and neutrophil extracellular traps (NETs) to generate a highly lethal environment that is essential for efficient microbe killing and degradation $[5,6]$.

On the other hand, many pathogens have evolved efficient strategies to outfox the weaponry of neutrophils. The main strategies can be divided into five categories: evading extravasation and chemotaxis, preventing opsonization and phagocytosis, surviving inside the neutrophil, inducing cell 


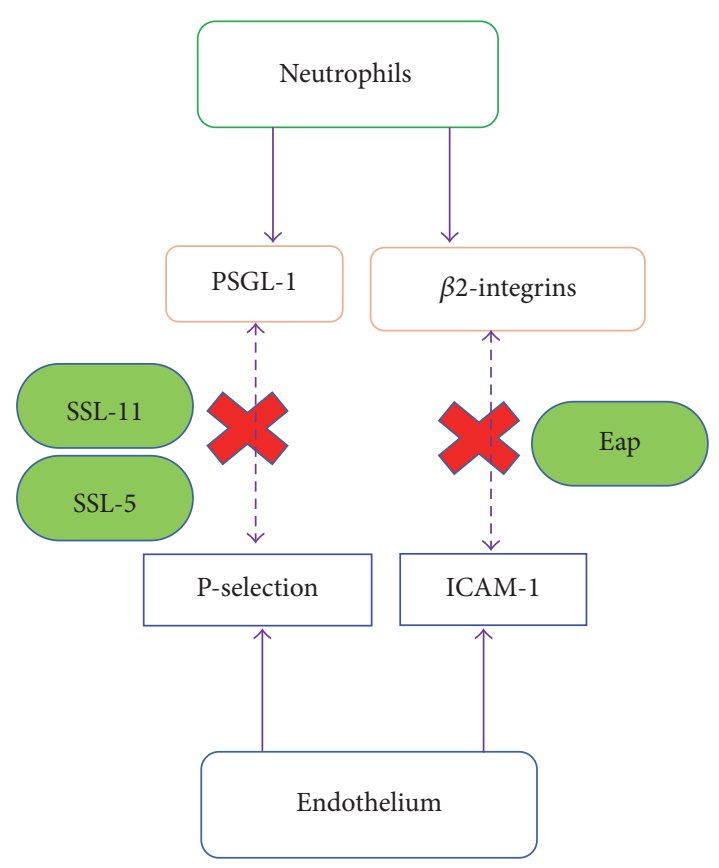

(a)

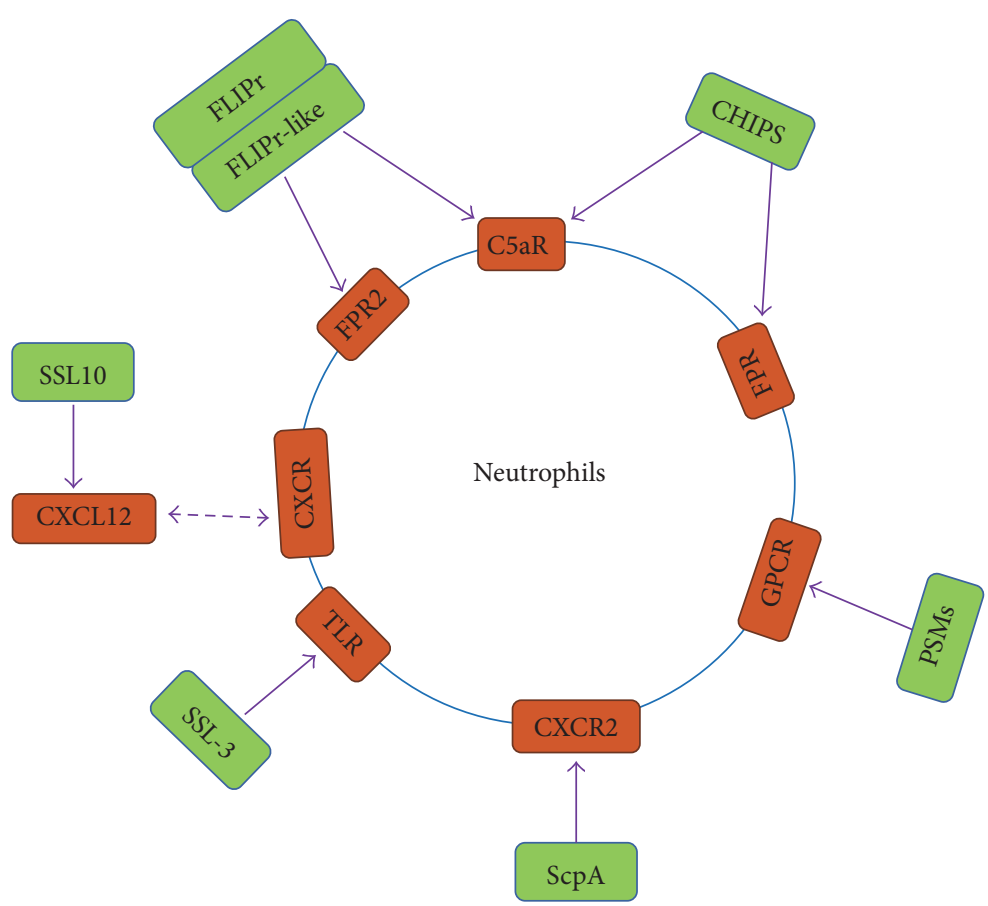

(b)

FIGURE 1: Evasion of neutrophil adhesion and transmigration. (a) Mechanisms by which Staphylococcus aureus subverts neutrophil extravasation. (b) Neutrophil attack and evasion of activation.

death, and avoiding killing in NETs [7, 8]. In this review, we will highlight the suite of mechanisms employed by neutrophils to clear bacterial infections and the corresponding counterattack mounted by bacterial pathogens.

\section{Neutrophil-Mediated Phagocytosis of Pathogenic Microorganism}

Initial elimination of invading pathogenic microorganism from human tissue is mediated by professional phagocytes. For efficient phagocytosis, neutrophils first need to leave the bloodstream and reach the site of infection, termed neutrophil recruitment. Furthermore, initiation of phagocytosis requires decoration of bacteria with opsonins that are recognized by specific surface receptors, of which process is termed opsonization of microbes. Lastly, neutrophils express numerous receptors that recognize microbe via binding its specific molecules and host proteins (such as IgG and complement), termed pathogen recognition.

2.1. Neutrophils Migrate from the Bloodstream to the Site of Infection. Upon the breach of epithelium by pathogens, as the first responder to microbial invasion, neutrophils leave the bloodstream and move to the site of infection. This recruitment process consists of three major steps: initiation of adherence to activated endothelial cells and rolling, neutrophil arrest caused by firm attachment to the endothelium, and finally migrating across the endothelial barrier to the infection site.
The initial step occurs through the interaction between the glycoprotein P-selectin glycoprotein ligand-1 (PSGL-1) of neutrophils and P-selectin/E-selectin of endothelial cells [9] (Figure 1(a)). Owing to this loose adhesion, neutrophils can roll along the endothelial cells. The second step is dependent on the interaction between $\beta 2$ integrins (such as LFA- 1 and Mac-1) present on the surface of neutrophils and intercellular adhesion molecule 1 (ICAM-1) present on endothelial cells (Figure 1(a)). The final step is triggered by chemokines released by host cells and bacterial products. Host-derived chemokine, such as IL8, GRO- $\alpha$, granulocyte chemotactic protein 2 , and complement component $\mathrm{C} 5 \mathrm{a} / \mathrm{C} 3 \mathrm{a}$, are potent proinflammatory mediators that are used to recruit additional neutrophils to areas of infection. Furthermore, neutrophils migration also can be elicited by bacteria-derived chemokine, such as lipoteichoic acid or $\mathrm{N}$-formyl peptides (fMLP).

2.2. Neutrophil Phagocytosis Is Dependent on Opsonization of Microbes. Initiation of neutrophil phagocytosis is dependent on opsonization of the target microbes that are recognized by specific surface receptors of neutrophils. Complement components and immunoglobulins (Igs) are the predominant factor in serum that enables efficient opsonization. The human complement system is composed of more than 30 proteins and is activated by any one of three routes: the classical pathway, the lectin pathway, and the alternative pathway (Figure 2). Complement system uses three independent pathways to distinguish bacteria from host cells and then can rapidly 


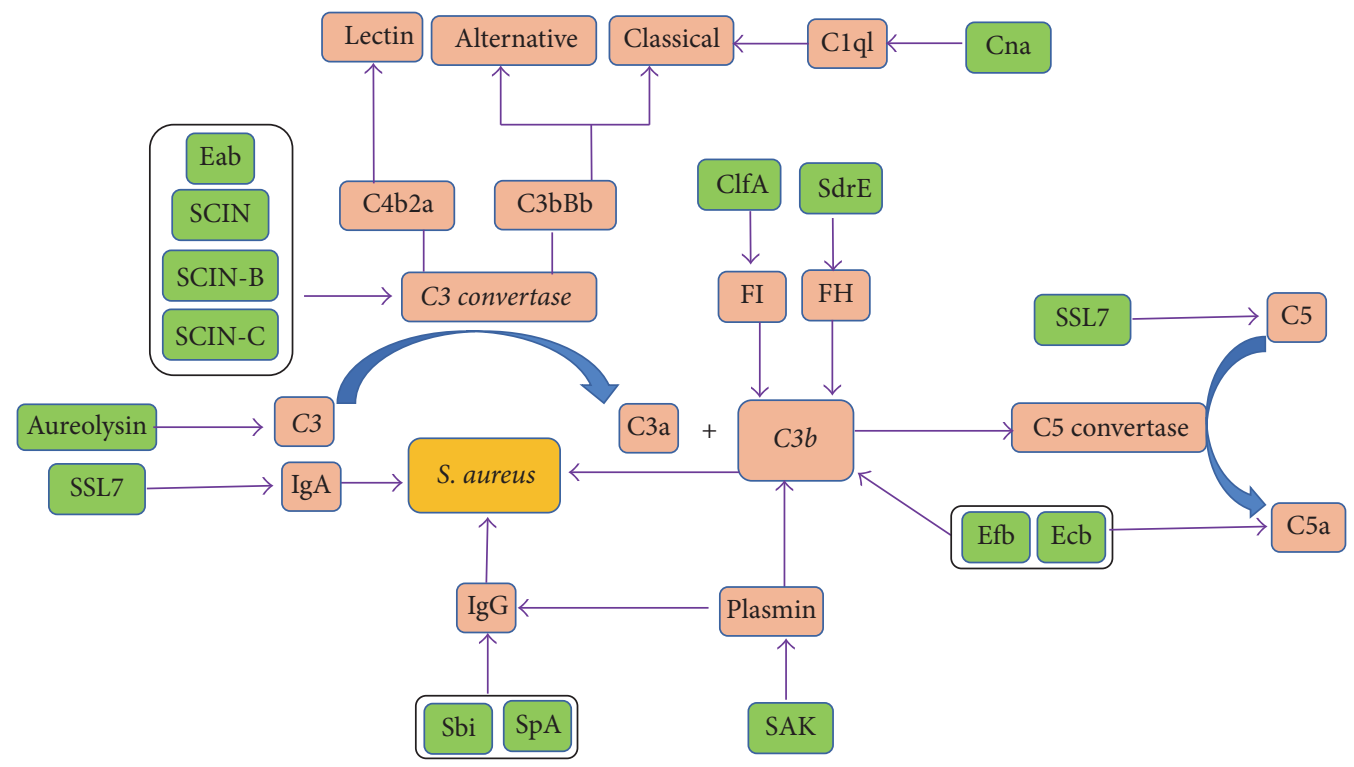

FIGURE 2: Staphylococcus aureus was interfered with chemotaxis and activation of complement.

recognize and opsonize bacteria or kill gram-negative bacteria directly by formation of the membrane attack complex [10]. All three pathways converge in the assembly of a C3 convertase, which are enzyme complexes that consist of $\mathrm{C} 4 \mathrm{~b} 2 \mathrm{a}$ and $\mathrm{C} 3 \mathrm{bBb}(\mathrm{C} 4 \mathrm{~b} 2 \mathrm{a}$ for the classical and lectin pathways and $\mathrm{C} 3 \mathrm{bBb}$ for the alternative pathway). The $\mathrm{C} 3$ convertase catalyzes the key reaction in complement activation: cleavage of complement protein $\mathrm{C} 3$ results in release of anaphylactic agents $\mathrm{C} 3 \mathrm{a}$ and $\mathrm{C} 3 \mathrm{~b}$. Most of $\mathrm{C} 3 \mathrm{~b}$ is further processed into iC3b by complement factor $\mathrm{H}$ and complement factor I (Figure 2). At high local concentrations of $\mathrm{C} 3 \mathrm{~b}$, the $\mathrm{C} 3$ convertase is changed into a C5 convertase, which cleaves $\mathrm{C} 5$, resulting in release of the potent chemoattractants $\mathrm{C} 5 \mathrm{a}$, and C5b, which initiates the lytic pathway when deposited on gram-negative bacteria, thereby amplifying the opsonization process.

Igs, which are the second most abundant protein in serum/plasma, play an important role in opsonization of bacteria and subsequent recognition by specific Fc receptor present on the surface of neutrophils. Several Ig subtypes ( $\operatorname{IgG}, \operatorname{IgM}$, and $\operatorname{Ig} \mathrm{A}$ ) have roles in microbial infection control (Figure 2). Different subclasses of Igs display distinct differences in complement activation and $\mathrm{Fc} \gamma$ receptor $(\mathrm{Fc} \gamma \mathrm{R})$. Normal human neutrophils express two major Fc $\gamma$ Rs, Fc $\gamma$ RII and Fc $\gamma$ RIIIB, and do not express the Fc $\gamma$ R1 [11]. IgG can activate the classical complement pathway and neutralize toxins or other bacterial virulence factors. IgM, owing to its polymeric nature, is particularly effective at complement activation and opsonization. In contrast to IgG and IgM, IgA does not activate the complement system.

2.3. Receptor-Mediated Pathogen Recognition and Phagocytosis. Once neutrophils migrate to the site of infection, the opsonized pathogen can be recognized and phagocytized via receptor-mediated uptake into a vacuole within the cell. Similar to other phagocytes, such as macrophages, neutrophils express a large number of receptors including patternrecognition receptors (PRRs), G protein-coupled receptors (GPCRs), and opsonic receptors. These receptors can recognize microbe-associated molecular patterns (MAMPs) and host proteins (such as IgG and complement) which were used to opsonize the microbe (Figure 1(b)). The PRRs can recognize pathogen-associated molecular patterns (PAMPs), such as bacterial DNA, lipopolysaccharide, peptidoglycan, and lipoteichoic acids. The major types of PRRs on neutrophils include Dectin-1 (recognizing fungal $\beta$-glucan), triggering receptor expressed on myeloid cells-1 (TREM-1, recognizing bacteria and fungi) [12], and toll-like receptors (TLRs, recognizing lipids, carbohydrates, and peptide). GPCRs, which are expressed in the surface of neutrophils, can recognize bacterial products as well as endogenous molecules released during inflammation. The formyl peptide receptors 1 (FPR1) and its homologue FPR2 belong to the GPCRs family, recognize Nformylated proteins and peptides (fMLP), and consequently induce and potentiate chemotaxis, phagocytosis, and the generation of oxidative burst in neutrophils (Figure 1(b)). Invasive bacterial pathogens are opsonized with complement (e.g., C3b) and antibody (e.g., IgG), recognized by opsonic receptors, including $\mathrm{Fc} \gamma \mathrm{Rs}$ and the complement receptors (CRs), respectively. Activation of opsonic receptors rapidly enhances the efficiency of phagocytosis and is critical for neutrophil-mediated pathogen killing [13].

\section{Pathogen Killing by Neutrophils}

Neutrophils are the first line of innate immune cells arriving at the site of bacterial inoculation, where they exert diverse antimicrobial mechanisms to prevent pathogen dissemination to normally sterile sites. The process by which neutrophils kill invading pathogens depends on three primary mechanisms [14]: production of highly toxic reactive oxygen 
species (ROS) in the pathogen-containing vacuole; fusion of neutrophil granules, containing various antimicrobial mediators to the vacuole; NETs formation. These steps may also contribute to inflammatory diseases in which ligands are deposited on tissue components.

3.1. Phagocytic Uptake of Bacteria Triggers Production of ROS. Coincident with phagocytosis of bacteria, neutrophils produce an oxidative burst resulting in the rapid release of high levels of bactericidal reactive chemical species under the catalyzation of NADPH oxidase, myeloperoxidase (MPO), or nitric oxide (NO) synthetase [15]. NADPH oxidase is responsible for the generation of ROS, such as superoxide anion $\left(\mathrm{O}_{2}{ }^{-}\right)$, hydrogen peroxide $\left(\mathrm{H}_{2} \mathrm{O}_{2}\right)$, and hydroxyl radicals $\left(\mathrm{HO}^{\circ}\right)$. The NADPH oxidase functions by shuttling electrons across the phagosomal membrane from cytosolic NADPH to molecular oxygen to produce $\mathrm{O}_{2}{ }^{-}$. By superoxide dismutase (SOD), the superoxide anion is readily converted to hydrogen peroxide. $\mathrm{H}_{2} \mathrm{O}_{2}$ and $\mathrm{O}_{2}{ }^{-}$can combine to generate the highly reactive $\mathrm{HO}^{\circ}$ via the Haber-Weiss reaction, which requires a metal such as iron. As a microbicidal agent, $\mathrm{HO}^{\circ}$ was probably not found in intact cells because that lactoferrin inhibits the generation of $\mathrm{HO}^{\circ}$ and other free radical reactions by binding free copper and iron. Against certain pathogens, such as Aspergillus, NADPH oxidase is critical for host defense independently of proteinases, and its importance is revealed in that patients who lack any one of the oxidase subunits suffer from chronic granulomatous disease (CGD) [16].

MPO converts hydrogen peroxide to primarily hypochlorous acid $(\mathrm{HOCl}) . \mathrm{HOCl}$ is the most bactericidal oxidant in neutrophils. Notably, hydrogen peroxide and other secondary oxygen derivatives such hydroxyl radical, chloramines, and $\mathrm{HOCl}$ can inactivate iron-sulphur proteins, membrane proteins, and the origin of replication site for DNA synthesis, which play a critical role in the killing of pathogenic bacteria [17]. Indeed, some patients, whose neutrophils lacked MPO, were thought to be immunodeficient [18]. And MPO knockout mice have also shown an undue susceptibility to bacterial and fungal infections [19].

Oxidative deamination of L-arginine by nitric oxide (NO) synthetase generates NO that together with superoxide anion forms reactive nitrogen intermediates with antimicrobial activity [20]. NO, a short-lived (half-life of a few seconds), highly reactive molecule, is produced by inducible nitric oxide synthase (iNOS), which is present in primary granules and is induced upon neutrophil priming (via TNF, IL-1, or IFN- $\gamma$ ) and during bacterial infection. NO production complements ROS production by neutrophils to exert antibacterial functions.

3.2. Phagocytic Uptake of Bacteria Triggers Production of Degranulation. Pathogens sequestered by neutrophils are trafficked to and fused with the phagosome in a process called degranulation, leading to the killing of invading pathogens in a process involving the release and action of proteinases and peptidases (Table 1). Functionally, the granules can be subdivided into three different classes based on the contents of their matrices and their integral membrane proteins: azurophilic granule, specific granule, and gelatinase granule. Neutrophils are "prepacked" with multiple types of granules that fuse with phagocytic vacuoles to facilitate pathogens destruction. Moreover, granules also help to initiate an inflammatory response and contain alkaline phosphatase, lactoferrin, lysozyme, and NADPH oxidase.

Azurophil (or primary) granules are the first to be produced and contain MPO and a spectrum of neutrophil serine proteases (NSPs): cathepsin G (CG), neutrophil elastase $(\mathrm{NE})$, proteinase $3(\mathrm{PR} 3)$, and the recently discovered neutrophil serine protease-4 (NSP4) [30, 90]. NSPs are critical for the effective functioning of neutrophils and greatly contribute to immune protection against bacterial infections [27]. NSPs are currently believed to have three functions. (1) NSPs can directly kill bacterial cell. NE has been shown to directly kill the gram-negative bacteria $E$. coil by cleavage of its outer membrane protein $\mathrm{A}$, resulting in loss of membrane integrity and cell death. In vivo, the concerted action of NE, CG, and PR3 can kill S. pneumonia within phagocytic vacuole. (2) NSPs can cleave host proteins to generate antimicrobial peptides. The best-known example is that PR3 that has been shown to cleave hCAP-18 to generate the antimicrobial peptide LL-37. (3) NSPs can attenuate bacterial virulence by inactivating factors required for pathogenesis. Shigella flexneri mobility proteins Ics A and IpaA-C can be cleaved by NE, consequentially preventing its dissemination into the cytoplasm of neutrophils. Similar to NE, CG can cleave the $S$. aureus adhesin clumping factor $\mathrm{A}$ and remove its active domain. Together, these NSPs are critical for the effective functioning of neutrophils and immune protection against bacterial infections [27].

In addition, neutrophils also contain a full-length cationic antimicrobial protein, bactericidal/permeability-increasing protein (BPI) in azurophil granules [91]. BPI possesses three types of anti-infective activities: direct antimicrobial activity, neutralizing endotoxin activity through direct binding of LPS, and opsonic activity. BPI binding to LPS results in increased bacterial permeability, hydrolysis of bacterial phospholipids, and death of the bacterium. In addition to its well-documented anti-infective properties, BPI has also been shown to possess additional bioactivities, such as accelerating apoptosis, binding the vascular endothelial growth factor (VEGF), and inhibiting migration of human umbilical vein endothelial cells.

The specific granules are smaller with $0.1 \mu \mathrm{m}$ diameter and formed after azurophilic granules. These granules do not contain MPO and are characterized by the presence of the glycoprotein lactoferrin. They primarily contain a wide range of antimicrobial compounds including calprotectin, lactoferrin, neutrophil gelatinase-associated lipocalin (NGAL), hCAP-18, and lysozymes. Calprotectin, also called S100A, is a critical factor in the innate immune response to infection and has been shown to inhibit microbial growth through chelation of nutrient $\mathrm{Mn}^{2+}$ and $\mathrm{Zn}^{2+}$, resulting in reprogramming of the bacterial transcriptome [92]. Lactoferrin, also called lactotransferrin, is an iron-binding glycoprotein present in most biological fluids of mammals and is released from neutrophil granules during inflammatory responses [93, 94]. Lactoferrin possesses a number of types of antibacterial activities: (1) blocking the entry of bacterial pathogens competitively 
TABLE 1: Mechanism of action of neutrophil antimicrobial proteins/peptide.

\begin{tabular}{|c|c|c|c|c|}
\hline $\begin{array}{l}\text { Antimicrobial } \\
\text { protein/peptide }\end{array}$ & $\begin{array}{c}\text { Direct antimicrobial } \\
\text { mechanism }\end{array}$ & $\begin{array}{c}\text { Alternative antimicrobial } \\
\text { mechanism }\end{array}$ & $\begin{array}{l}\text { Subcellular } \\
\text { localization }\end{array}$ & Ref. \\
\hline$\alpha$-Defensins & $\begin{array}{l}\text { Membrane-active; inhibition } \\
\text { of DNA, RNA, protein, } \\
\text { bacterial cell wall synthesis }\end{array}$ & $\begin{array}{l}\text { Opsonisation of bacteria/ROS } \\
\text { formation }\end{array}$ & $\begin{array}{l}\text { Primary granules, } \\
\text { NETs }\end{array}$ & {$[21]$} \\
\hline LL-37 & Transmembrane pore-forming & ROS formation & $\begin{array}{l}\text { Secondary granules, } \\
\text { NETs }\end{array}$ & {$[22]$} \\
\hline BPI & $\begin{array}{c}\text { Hydrolysis of bacterial } \\
\text { phospholipids by binding to } \\
\text { LPS }\end{array}$ & $\begin{array}{c}\text { Inhibiting cytokine liberation } \\
\text { by binding to CD14 }\end{array}$ & Primary granules & {$[23,24]$} \\
\hline Histones & Membrane-active & NETs formation & Nucleus, NETs & {$[25]$} \\
\hline Lysozyme & Degrades bacterial cell wall & NETs formation & Lysosomes & {$[5,26]$} \\
\hline PR3 & $\begin{array}{c}\text { Proteolytic activity; degrading } \\
\text { virulence factors }\end{array}$ & NETs formation & $\begin{array}{c}\text { Primary } \\
\text { granules/NETs }\end{array}$ & {$[27-29]$} \\
\hline $\mathrm{NE}$ & $\begin{array}{c}\text { Proteolytic activity; degrading } \\
\text { virulence factors }\end{array}$ & NETs formation & $\begin{array}{c}\text { Primary } \\
\text { granules/NETs }\end{array}$ & {$[27-29]$} \\
\hline CatG & Proteolytic activity & $\begin{array}{l}\text { NETs formation; ROS } \\
\text { formation }\end{array}$ & $\begin{array}{c}\text { Primary } \\
\text { granules/NETs }\end{array}$ & {$[28,29]$} \\
\hline NSP4 & Trypsin-like activity & Unknown & Primary granules & [30-32] \\
\hline Azurocidin & Membrane-active & Opsonisation of bacteria & Primary granules & {$[33]$} \\
\hline Lactoferrin & $\begin{array}{l}\text { Altering bacterial growth by } \\
\text { binding to iron; increase in } \\
\text { membrane permeability by } \\
\text { binding to the lipid A }\end{array}$ & $\begin{array}{l}\text { Decreasing the release IL-1, } \\
\text { IL-2, and TNF } \alpha \text {; Suppressing } \\
\text { NETs release }\end{array}$ & $\begin{array}{c}\text { Secondary } \\
\text { granules/NETs }\end{array}$ & {$[34-37]$} \\
\hline Calprotectin & $\begin{array}{l}\text { Altering bacterial growth by } \\
\text { sequestering } \mathrm{Mn}^{2+} \text { and } \mathrm{Zn}^{2+}\end{array}$ & $\begin{array}{l}\text { Inhibition of } \mathrm{Mn}^{2+} \text {-dependent } \\
\text { bacterial superoxide defenses; } \\
\text { NETs formation }\end{array}$ & Secondary granules & {$[38,39]$} \\
\hline PTX3 & $\begin{array}{c}\text { As a soluble pattern } \\
\text { recognition receptor in innate } \\
\text { immunity }\end{array}$ & NETs formation & $\begin{array}{c}\text { Secondary } \\
\text { granules/NETs }\end{array}$ & {$[40]$} \\
\hline NADPH oxidase & $\begin{array}{c}\text { Generation of superoxide } \\
\text { anion }\end{array}$ & NETs formation & Lysosomes & {$[41]$} \\
\hline MPO & $\begin{array}{l}\text { Generation of hypochlorous } \\
\text { acid }\end{array}$ & NETs formation & Lysosomes & {$[18,42,43]$} \\
\hline Platelets & $\begin{array}{l}\text { Activating neutrophils to } \\
\text { release NETs }\end{array}$ & NETs formation & NETs & {$[44]$} \\
\hline NGAL & $\begin{array}{l}\text { Inhibit bacteria growth by } \\
\text { capturing and depleting } \\
\text { siderophores }\end{array}$ & $\begin{array}{l}\text { Acting as a growth and } \\
\text { differentiation factor in } \\
\text { multiple cell type }\end{array}$ & Secondary granules & {$[45,46]$} \\
\hline
\end{tabular}

binding onto cell receptors, such as glycosaminoglycans; (2) degrading protein virulence produced by bacteria, such as $H$. influenza and E. coil, through proteolysis; (3) preventing bacterial adhesion through competing bacterial adhesion sites on bacteria and host cells [95].

The tertiary granules, also named gelatinase granules, are smaller than specific granules and are both MPO- and lactoferrin-negative. These granules contain few antimicrobials but serve as a storage location for a number of metalloproteases, such as gelatinase and leukolysin. These granules may represent one end of the population of granules formed during neutrophil maturation.

3.3. Neutrophil Extracellular Traps Killing Bacteria. In addition to pathogens phagocytosis and subsequent reactive species- and enzyme-dependent pathogen destruction, neutrophils also exert antibacterial activity through neutrophil extracellular traps (NETs), which was first described by Brinkmann et al. in 2004 [96]. Sensing the entry of bacteria, neutrophils extrude a mesh-like structure consisting of DNA/histones and are peppered with granule-derived antimicrobial peptides and enzymes, a process termed NETosis. NETs are composed of DNA strands associated with histones and decorated with about 20 different proteins, including NE, CG, PR3, MPO, lactoferrin, pentraxin 3 [40], high mobility group protein B1, LL37, and buforin II [97]. Mitochondria can also serve as a source of DNA for NET formation. The NETs are capable of ensnaring microbes by localizing and trapping pathogens within a sticky meshwork of chromatin. Furthermore, NETs facilitate pathogen 


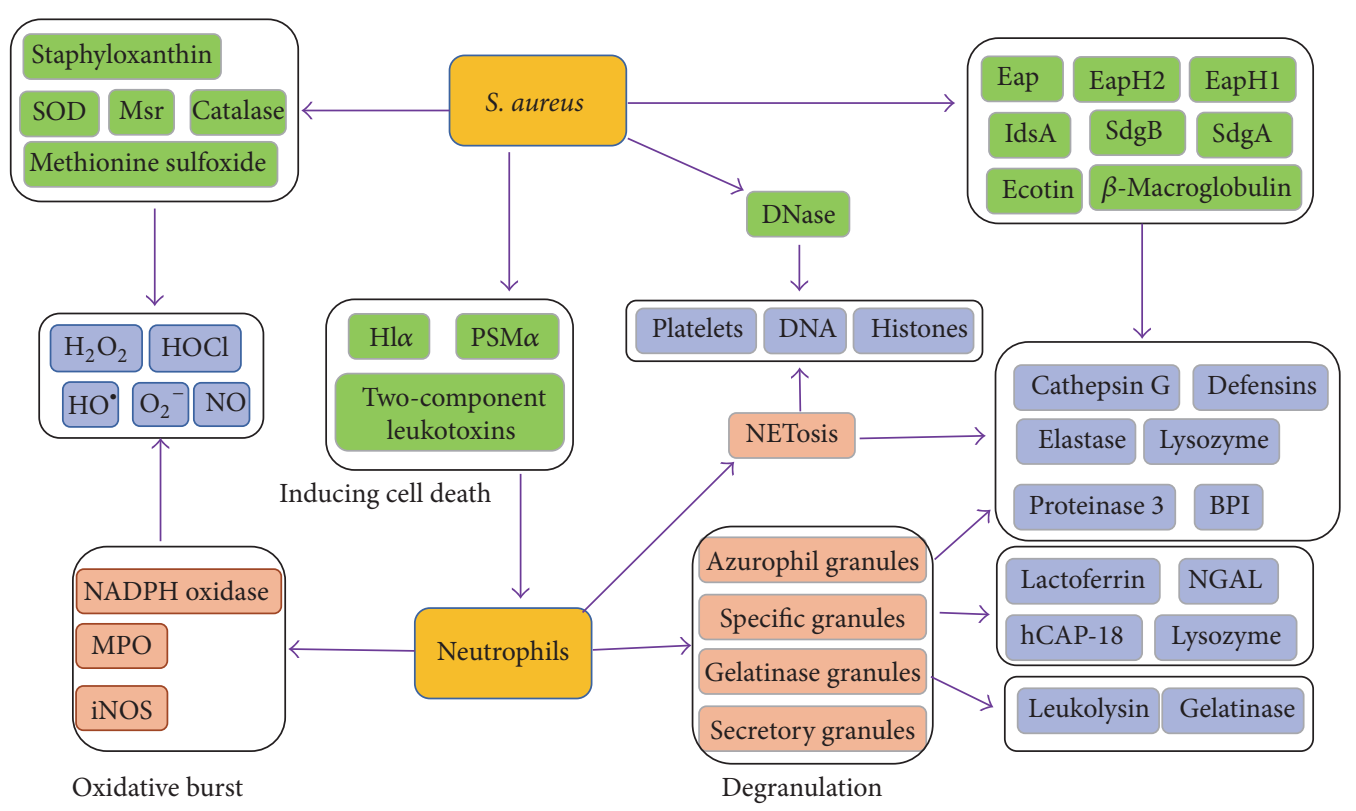

FIGURE 3: Direct antimicrobial mechanisms from neutrophils and the S. aureus counterattack. Neutrophils are equipped with multiple antiinfective strategies including the bacterial uptake (phagocytosis), the phagolysosomal degradation of bacteria via reactive oxygen species (oxidative burst), the release of antimicrobial molecules (degranulation), and the formation of a web-like structure composed of chromatin, histones, and antimicrobials (neutrophil extracellular traps, NETs). S. aureus is equipped with a magnitude of neutrophil resistance factors (green boxes) allowing the pathogen to uniquely counteract each antibacterial strategy of neutrophils.

exposing to highly concentrate antimicrobial peptides and enzymes, such as MPO, neutrophil elastase, LL-37, S100A, and lactoferrin-chelating proteins [98]. Along with the chromatin network, these antimicrobial agents are concentrated and the potential for synergistic action is enhanced. When neutrophils extrude a meshwork of chromatin to form NETs, it is not an end point for neutrophils and anuclear neutrophils can also migrate and retain the necessary components to kill bacteria through phagocytosis and formation of mature phagosomes [99].

The molecular mechanisms details of NETs formation are tightly linked to the production of ROS. The magnitude and duration of ROS production play an important role in promoting NETs formation and may be a major role in determining the fate of the neutrophil. In addition, individuals lacking MPO and NADPH oxidase, two key enzymes in the ROS cascade, are unable to make NETs and suffer from debilitating infections [100]. However, ROS are not the only vital roles in NETs formation and decondensation of chromatin is also critical for proper NETs formation. Neutrophil elastase was shown to partially degrade histones and further leads to decondensation of chromatin, which is also a pivotal event in the process of NETs formation [101].

NETosis also has the dark side: apart from this antimicrobial function, the cytotoxicity of NETs can be harmful to the host if their release is inappropriately controlled. Excessive NETs formation is linked to various neutrophil-mediated pathologies, including vasculitis, sepsis, and systemic lupus erythematosus nephritis. NETs also induce platelet procoagulant activation, which can lead to significant thrombosis and vascular injury. Excessive NETs formation and endothelial cell activation are also associated with preeclampsia of pregnancy [102].

\section{4. “Catch Me If You Can": How Pathogens Evade Antibacterial Arsenal of Destruction by Neutrophils}

To promote its own survival within the host, bacterial pathogens have evolved an array of specific mechanisms to overcome destructions by neutrophils (Figure 3, Table 2). $S$. aureus, the culprit of many types of infections, exhibits many characteristics of antineutrophils pathogens [103].

4.1. Inhibition of Neutrophil Recruitment. Counter measures adopted by pathogen may affect these steps to inhibit neutrophil recruitment. For instance, staphylococcal superantigen-like 5 (SSL5) can block neutrophil adhesion to endothelial cells by binding to PSGL-1 and consequently blocking its interaction with the natural ligand P-selectin [104]. SSL5 and other family members also inhibit leukocyte responses to chemokines, such as CXC, CC, CX3C, and CXCL12, and to the complement fragments C3a and C5a. Moreover, extracellular adherence protein (Eap) generated by $S$. aureus can bind and inhibit ICAM-1, a crucial molecule used to facilitate the neutrophils firm adhesion of endothelial cells. Furthermore, bacteria can secrete a variety of proteases, leading to degradation of chemokines. Chemotaxis inhibiting protein (CHIPS), a protein freely secreted by $S$. aureus, binds directly to the C5a receptor and formyl peptide receptors (FPRs) and thereby inhibits neutrophils recruitment $[105,106]$. As a homologue of CHIPS in S. aureus, FPR-like 1 inhibitory proteins (FLIPr 
TABLE 2: Neutrophil antibacterial functions subverted by S. aureus. S. aureus produces a large suite of virulence factors to counteract specific neutrophil clearance mechanisms during the pathogenesis of invasive infection.

\begin{tabular}{|c|c|c|c|}
\hline Virulence factor & Targets & Function & Ref. \\
\hline SSL-5 & PSGL1/GPCRs & Recruitment/chemotaxis inhibition & {$[47,48]$} \\
\hline SSl-6 & PSGL1 & Recruitment inhibition & [49] \\
\hline SSl-11 & PSGL1 & Recruitment inhibition & {$[50]$} \\
\hline SSl-3 & TLR2 & Chemotaxis inhibition & {$[51,52]$} \\
\hline SEIX & PSSG1 & Recruitment inhibition & [49] \\
\hline ScpA & CXCR2 & Chemotaxis inhibition & {$[53]$} \\
\hline CHIPS & FPR1, C5aR & Chemotaxis inhibition & {$[54,55]$} \\
\hline FLIPr & FPR2 & Chemotaxis inhibition & {$[56,57]$} \\
\hline FLIPrL & FPR1, FPR2 & Chemotaxis inhibition & {$[56,57]$} \\
\hline PSMs & FPR2 & Chemotaxis inhibition/neutrophils lysis & {$[56,58]$} \\
\hline Eap & ICAM1/C4b/NE/CG/PR3 & Recruitment/phagocytic inhibition & [59] \\
\hline Aureolysin & $\mathrm{C} 3$ & Complement inhibition & {$[60]$} \\
\hline SCIN & $\mathrm{C} 3 \mathrm{bBb}$ & Complement inhibition & {$[61,62]$} \\
\hline SCIN-B/C & $\mathrm{C} 3 \mathrm{bBb}$ & Complement inhibition & {$[61,62]$} \\
\hline Efb & $\mathrm{C} 3 \mathrm{~b}$ & Complement inhibition & {$[63]$} \\
\hline Ecb & $\mathrm{C} 3 \mathrm{~b}$ & Complement inhibition & {$[64]$} \\
\hline SSL7 & $\operatorname{Ig} \mathrm{A} / \mathrm{C} 5$ & Phagocytosis/complement inhibition & {$[65]$} \\
\hline SSL10 & IgG & Phagocytosis inhibition & {$[66]$} \\
\hline SAK & $\mathrm{C} 3 / \mathrm{IgG}$ & Phagocytosis inhibition & {$[67]$} \\
\hline Sbi & IgG/C3/factor $\mathrm{H}$ & Phagocytosis inhibition & {$[68,69]$} \\
\hline SpA & IgG & Phagocytosis inhibition & {$[70]$} \\
\hline ClfA & Factor I & Phagocytosis inhibition & {$[56]$} \\
\hline SOK & Unknown & Phagocytosis inhibition & {$[71]$} \\
\hline $\mathrm{CP}$ & Unknown & Phagocytosis inhibition & {$[72]$} \\
\hline SdrE & Factor $\mathrm{H}$ & Complement inhibition & [73] \\
\hline IsdH & $\mathrm{C} 3 \mathrm{~b}$ & Complement inhibition & {$[74]$} \\
\hline Cna & $\mathrm{Clq}$ & Complement inhibition & {$[75]$} \\
\hline LukAB & $\alpha \mathrm{M}$ integrin & Neutrophils lysis & {$[76]$} \\
\hline LukED & CCR5/CXCR1/CXCR2 & Neutrophils lysis & {$[77]$} \\
\hline LukMF & Not known & Neutrophils lysis & {$[78]$} \\
\hline PVL & $\mathrm{C} 5 \mathrm{aR}$ & Neutrophils lysis & [79] \\
\hline Hla & $\mathrm{C} 5 \mathrm{aR}$ & Neutrophils lysis & {$[80]$} \\
\hline Staphyloxanthin & Unknown & Resistance to ROS & {$[81]$} \\
\hline KatA & Hydrogen peroxide & Resistance to ROS & {$[82]$} \\
\hline AhpC & Hydrogen peroxide & Resistance to ROS & {$[82]$} \\
\hline Msr & Hydrogen peroxide & Resistance to ROS & {$[83]$} \\
\hline AdsA & Adenosine & Resistance to ROS & [84] \\
\hline IsdA & Fibrinogen & Resistance to lactoferrin & {$[85]$} \\
\hline OatA & Peptidoglycan & Resistance to lysozyme & {$[86,87]$} \\
\hline EapH1 & NSPs & Resistance to NSPs & {$[88]$} \\
\hline EapH2 & NSPs & Resistance to NSPs & {$[88]$} \\
\hline Nuclease & DNA & Resistance to NETs & [89] \\
\hline
\end{tabular}

and FLIPr-like) bind and inhibit FPR1 as well as C5aR and then impair neutrophil chemotaxis. Another cysteine protease secreted by S. aureus is staphopain A, which inactivates CXCR 2 chemokines by cleaving its $\mathrm{N}$-terminal domain and then inhibits neutrophil activation and recruitment [53]. In addition, SSL3 specifically binds and inhibits TLR2 activation, which is critical for host defense against $S$. aureus [107].

4.2. Preventing Phagocytosis. S. aureus has successfully developed ways to evade the complement system by secretion of specific complement inhibitors (Figure 2, Table 2). The 
secreted factors described below allow bacteria to either diminish or delay the detrimental effects of an innate immune attack, thereby generating a window of opportunity to replicate and establish a microenvironment conducive to bacterial survival and disease pathogenesis $[108,109]$.

4.2.1. Cleavage of IgG. SSL7 binds host IgA and complement component $\mathrm{C} 5$, inhibiting generation of $\mathrm{C} 5 \mathrm{a}$, phagocytosis, and production of phagocyte reactive oxygen species. $S$. aureus expresses two surface-anchored proteins, staphylococcal protein A (SpA) and staphylococcal immunoglobulinbinding protein (Sbi), which impair IgG function. SpA possesses five immunoglobulin-binding repeat domains. Each domain can bind the Fc-part of IgG, thereby blocking the interaction with $\mathrm{Fc}$ receptors on neutrophils. Sbi consists of four small domains, of which two (Sbi-I and Sbi-II) can bind IgG [110-112].

4.2.2. Direct Inactivation of C3 Convertases. It has been shown that SCIN and its homologues (SCIN-B and SCINC), as strongly antiphagocytic molecules, modulate all the three complement pathways through the unique interaction with C3 convertases [61]. Extracellular fibrinogen-binding protein (Efb) and its homologue extracellular complementbinding protein $(\mathrm{Ecb})$ can modulate the alternative pathway convertase by binding to the C3b molecule directly [113]. S. aureus secretes the $16 \mathrm{Kda} \mathrm{Efb}$ that binds two different plasma proteins using separate domains: the Efb $\mathrm{N}$-terminus binds to fibrinogen, while the C-terminus binds complement C3b.

\subsubsection{Binding or Cleavage of Human Convertase Regulators.} $S$. aureus recruits the complement regulatory protein factor $\mathrm{H}(\mathrm{fH})$ and factor I (fI) to its surface to inhibit the alternative pathway of complement activation. The surface-associated protein $\mathrm{SdrE}$, as an $\mathrm{fH}$-binding protein, enhances recruitment of $\mathrm{fH}$ which resulted in increased $\mathrm{iC} 3 \mathrm{~b}$ generation [73]. The clumping factor A (ClfA) of S. aureus binds to complement regulator factor I and increases factor I cleavage of $\mathrm{C} 3 \mathrm{~b}$ [114-116]. Similar to ClfA, iron-regulated surface determinant protein $\mathrm{H}$ (IsdH) could act as a factor I-mimicking protease and directly trap factor I to the $S$. aureus surface, promoting cleavage of $\mathrm{C} 3 \mathrm{~b}$ [74].

4.2.4. Eliminating Opsonic Molecules from the Bacterial Surface. Staphylokinase (SAK) is a secreted protein that binds and activates surface-bound plasminogen into plasmin, which removes IgG as well as $\mathrm{C} 3 \mathrm{~b}$ from the bacterial surface, making this protein a unique antiopsonic molecule [67]. Aureolysin [60], a secreted metalloprotease, inhibits the deposition of $\mathrm{C} 3 \mathrm{~b}$ on $\mathrm{S}$. aureus surfaces and the release of the chemoattractant C5a. It has been shown that aureolysin cleaves the central complement protein C3 specifically in the $\alpha$-chain, close to the $\mathrm{C} 3$ convertase cleavage site, yielding active $\mathrm{C} 3 \mathrm{a}$ and C3b. The antiphagocytic activity of the capsule is well established and the quantity of capsule is decisive for $S$. aureus and virulence. Overexpression of capsular polysaccharides type 8 renders $S$. aureus more resistant to phagocytosis by neutrophils in vitro $[72,117]$.
4.3. Surviving inside the Neutrophil. The combined action of ROS and antimicrobial proteins generated by granules creates a lethal environment for microbes. However, S. aureus harbored by neutrophils can survive in the presence of extreme environment, although not replication [118]. This is because $S$. aureus has evolved many means to resist oxidant damage and antimicrobial proteins degradation, as well as surviving within phagosomes.

First of all, S. aureus strains can express five types of enzymes or pigment promoting resistance to oxidative killing by stimulated neutrophils, including superoxide dismutase, catalase, staphyloxanthin, methionine sulfoxide reductases (Msr), and adenosine synthase A (AdsA). Superoxide dismutase produced by $S$. aureus can convert superoxide anion to $\mathrm{H}_{2} \mathrm{O}_{2}$, which is then consumed to yield $\mathrm{O}_{2}$ and $\mathrm{H}_{2} \mathrm{O}$ by catalase, thereby eliminating oxidants generated by stimulated neutrophils. Furthermore, S. aureus strains also produce the pigment staphyloxanthin, which consumes oxidants and renders bacteria resistant to oxidant-dependent killing, protecting bacteria from singlet oxygen via an undefined mechanism. Msr is a highly conserved enzyme that repairs oxidative damage incurred within neutrophils, contributing to survival of bacteria within neutrophils. AdsA, a cell wall-anchored enzyme, can convert adenosine monophosphate to adenosine [119]. As a critical virulence factor, AdsA promotes staphylococcal synthesis of adenosine in blood, escaping from phagocytic clearance [84]. Adenosine is also known to inhibit neutrophil degranulation, adhesion to vascular surfaces, and superoxide burst [120]. These findings indicate that phagocytosed $S$. aureus devote significant energy and effort to selfpreservation rather than to growth and replication.

Bacteria pathogens have evolved two strategies to counteract human NSPs. The first one is modifications of bacterial NSPs substrates. For gram-positives, such as S. epidermidis and S. aureus, glycosyltransferases (SdgA and SdgB) are expressed to modify the serine-aspartate dipeptide repeats (SDR) of GLcNAc, which will protect these bacteria from proteolytic degradation by CG. The LPS of Gram-negatives, such as Neisseria meningitidis, are anchored to the outer membrane by lipid A. The lipid can be modified by phosphoethanolamine transferase to prevent proteolysis-independent killing by CG.

The second strategy is production of NSPs inhibitors. A recent study reports that $S$. aureus has evolved three highly specific NSPs inhibitors: extracellular adherence protein (Eap) and its smaller homologues EapH1 and EapH2 [88]. These proteins are very potent and specific inhibitors of NSPs and imply a crucial role for NSPs in the defense against $S$. aureus. Iron-regulated surface determinant protein $\mathrm{H}(\mathrm{Isd} H)$ is present in the surface of $S$. aureus, which binds to lactoferrin, the most abundant antistaphylococcal polypeptide [121]. IsdA confers resistance to killing by lactoferrin. In addition, recombinant IsdA was a competitive inhibitor of lactoferrin protease activity. Thus, IsdA can protect $S$. aureus against lactoferrin and acts as a protease inhibitor [122].

4.4. Inducing Cell Death by Cytolytic Toxins. Following phagocytosis of bacteria pathogens, neutrophils would kill most bacteria and have initial features typical of apoptosis. 
However, S. aureus can survive within these neutrophils and ultimately cause cytolysis. Recent studies have provided evidence that cytolytic toxins produced by $S$. aureus contribute to neutrophil lysis after phagocytosis [123]. Cytolytic toxins produced by $S$. aureus, including the phenol soluble modulins (PSMs), alpha-hemolysin ( $\mathrm{Hl} \alpha$ ), and two-component leukotoxins, facilitate neutrophil killing after phagocytosis [124]. PSMs were first identified in 1999 by hot phenol extraction from S. epidermidis culture filtrate, in which three peptides termed PSM $\alpha, \operatorname{PSM} \beta$, and $\operatorname{PSM} \gamma$ were identified. PSMs do not have uniform charge characteristics. PSM $\alpha$ s of $S$. aureus are positively charged, while $\operatorname{PSM} \beta$ peptides are all negatively charged, and the $\operatorname{PSM} \gamma$ is neutral [125]. In $S$. aureus, PSM $\alpha$ peptides have a pronounced ability to lyse human neutrophils, in which PSM $\alpha 3$ has by far the strongest activity. However, PSM $\gamma$ (also named $\delta$-toxin) has moderate cytolytic activity and the PSM $\beta$ peptides are noncytolytic. At the micromolar concentrations, $\operatorname{PSM} \alpha$ has the pronounced capacity to kill human neutrophils after phagocytosis by disrupting the cytoplasmic membrane [126]. While at nanomolar concentrations, PSM $\alpha$ may stimulate neutrophils and initiate proinflammatory responses including neutrophil chemoattraction, activation, and the release of IL8 [127]. Neutrophils sense PSMs via formyl peptide receptor 2 (FPR2), which may sense the amphipathic, $\alpha$-helical structure of PSMs rather than a specific amino acid sequence motif.

Panton-Valentine Leukocidin (PVL) is a prophageencoded pore-forming exotoxin, which mainly acts on neutrophils as a crucial virulence factor in necrotizing diseases. PVL is a staphylococcal bicomponent pore-forming toxin comprising the protein subunits LukS-PV and LukF-PV [128]. Initial binding of LukS-PV to the surface of target cells triggers secondary binding of LukF-PV and subsequently induces the assembly of lytic pore-forming [129]. PVLinduced pore formation is mediated by the human C5aR, which determines species specificity of PVL [79]. The C5aR can bind LukS-PV, which is a potent inhibitor of C5a-induced immune cell activation.

S. aureus $\alpha$-hemolysin ( $\alpha$-toxin, Hla) belongs to the class of small $\beta$-barrel pore-forming cytotoxins [130]. As a water soluble monomer, $\alpha$-hemolysin is capable of binding and oligomerization into a heptameric structure on neutrophils. Then, $\alpha$-hemolysin exhibits the main action on pore formation and neutrophils lysis after phagocytosis [131]. In other studies, $\alpha$-hemolysin has been suggested to directly disrupt the $S$. aureus phagosome and promote $S$. aureus escape to and replication in the cytoplasm [131]. S. aureus $\alpha$-hemoly$\sin$ facilitates the secretion of newly synthesized CXC chemokines into the airway and stimulates neutrophil homing in staphylococcus aureus pneumonia [132].

4.5. Avoiding Killing in NETs. In addition to phagocytosis and intracellular killing, neutrophils release NETs that capture and kill microbes in the extracellular space. Several bacterial pathogens have evolved sophisticated mechanisms to suppress, escape, and/or resist NETs. Expression of nucleases is one highly conserved anti-NET factor among bacteria, which can degrade NETs indicating that the chromatin functions as a scaffold and is a major component of the fibres. Interestingly, extracellular nucleases are found in several pathogenic bacteria including $S$. aureus, Clostridium perfringens, and $S$. pyogenes (group A Streptococcus, GAS) [133].

In addition to produce nucleases, GAS can also suppress NETs formation by degrading the neutrophil stimulatory chemokine IL-8 with peptidase SpyCEP or HA capsule engagement of the inhibitory neutrophil receptor Siglec-9. Other GAS resistance factors, including M1 protein, Scl-1 protein, and the GLCNAc side chain, contribute to GAS resistance to antimicrobial components.

\section{Conclusion}

The interaction between neutrophils and pathogens remains a fascinating subject. The host requires the action of neutrophils to fight invaders and the pathogens in turn must cope with neutrophil attacks in order to colonize the host [134]. Several pharmacological agents can be used to enhance neutrophil energy generation, antimicrobial activities, and treatment outcomes. For instance, hypoxia-inducible factor 1 (HIF-1), innate defense regulator peptides (IDRs), and vitamin B3 all enhance antimicrobial activities to provide prophylactic and therapeutic activity against bacterial pathogens in vivo. And tamoxifen [135] or anacardic acid [136] could boost NETs formation and bacterial killing of neutrophils. To overcome antibiotic resistant pathogens which harness the multifaceted antimicrobial properties of neutrophils, these host-directed strategies provide a critical new element to boost neutrophil function and minimize the risk for development of antibiotic resistance during infection.

\section{Competing Interests}

The authors declare that they have no competing interests.

\section{Acknowledgments}

This work was supported by the Foundation of Science and Technology Department of Henan Province under Grant 162300410233 and the Natural Science Foundation of Education Department of Henan Province under Grant 17A310015.

\section{References}

[1] N. Borregaard, "Neutrophils, from marrow to microbes," Immunity, vol. 33, no. 5, pp. 657-670, 2010.

[2] P. H. C. Leliefeld, C. M. Wessels, L. P. H. Leenen, L. Koenderman, and J. Pillay, "The role of neutrophils in immune dysfunction during severe inflammation," Critical Care, vol. 20, no. 1, article 73, 2016.

[3] C. Nathan, "Neutrophils and immunity: challenges and opportunities," Nature Reviews Immunology, vol. 6, no. 3, pp. 173-182, 2006.

[4] T. N. Mayadas, X. Cullere, and C. A. Lowell, "The multifaceted functions of neutrophils," Annual Review of Pathology: Mechanisms of Disease, vol. 9, pp. 181-218, 2014.

[5] A. W. Segal, "How neutrophils kill microbes," Annual Review of Immunology, vol. 23, pp. 197-223, 2005. 
[6] C. F. Urban, S. Lourido, and A. Zychlinsky, "How do microbes evade neutrophil killing?" Cellular Microbiology, vol. 8, no. 11, pp. 1687-1696, 2006.

[7] S. Döhrmann, J. N. Cole, and V. Nizet, "Conquering neutrophils," PLoS Pathogens, vol. 12, no. 7, Article ID e1005682, 2016.

[8] W. M. Nauseef, "Neutrophils, from cradle to grave and beyond," Immunological Reviews, vol. 273, no. 1, pp. 5-10, 2016.

[9] K. M. Rigby and F. R. DeLeo, "Neutrophils in innate host defense against Staphylococcus aureus infections," Seminars in Immunopathology, vol. 34, no. 2, pp. 237-259, 2012.

[10] J. R. Dunkelberger and W.-C. Song, "Complement and its role in innate and adaptive immune responses," Cell Research, vol. 20, no. 1, pp. 34-50, 2010.

[11] K. P. M. van Kesse, J. Bestebroer, and J. A. G. van Strijp, "Neutrophil-mediated phagocytosis of Staphylococcus aureus," Frontiers in Immunology, vol. 5, article 467, 2014.

[12] J. W. Ford and D. W. McVicar, "TREM and TREM-like receptors in inflammation and disease," Current Opinion in Immunology, vol. 21, no. 1, pp. 38-46, 2009.

[13] A. Mócsai, "Diverse novel functions of neutrophils in immunity, inflammation, and beyond," The Journal of Experimental Medicine, vol. 210, no. 7, pp. 1283-1299, 2013.

[14] B. Amulic, C. Cazalet, G. L. Hayes, K. D. Metzler, and A. Zychlinsky, "Neutrophil function: from mechanisms to disease," Annual Review of Immunology, vol. 30, pp. 459-489, 2012.

[15] D. Roos, R. van Bruggen, and C. Meischl, "Oxidative killing of microbes by neutrophils," Microbes and Infection, vol. 5, no. 14, pp. 1307-1315, 2003.

[16] M. Greenlee-Wacker, F. R. DeLeo, and W. M. Nauseef, "How methicillin-resistant Staphylococcus aureus evade neutrophil killing," Current Opinion in Hematology, vol. 22, no. 1, pp. 30-35, 2015.

[17] D. Odobasic, A. R. Kitching, and S. R. Holdsworth, "Neutrophil-mediated regulation of innate and adaptive immunity: the role of myeloperoxidase," Journal of Immunology Research, vol. 2016, Article ID 2349817, 11 pages, 2016.

[18] S. J. Klebanoff, "Myeloperoxidase: friend and foe," Journal of Leukocyte Biology, vol. 77, no. 5, pp. 598-625, 2005.

[19] V. I. Morozov, S. A. Pryatkin, M. I. Kalinski, and V. A. Rogozkin, "Effect of exercise to exhaustion on myeloperoxidase and lysozyme release from blood neutrophils," European Journal of Applied Physiology, vol. 89, no. 3-4, pp. 257-262, 2003.

[20] C. C. Winterbourn, A. J. Kettle, and M. B. Hampton, "Reactive oxygen species and neutrophil function," Annual Review of Biochemistry, vol. 85, pp. 765-792, 2016.

[21] E. Cardot-Martin, J. S. Casalegno, C. Badiou et al., “ $\alpha$-defensins partially protect human neutrophils against Panton-Valentine leukocidin produced by Staphylococcus aureus," Letters in Applied Microbiology, vol. 61, no. 2, pp. 158-164, 2015.

[22] L. Frasca and R. Lande, "Role of defensins and cathelicidin LL37 in auto-immune and auto-inflammatory diseases," Current Pharmaceutical Biotechnology, vol. 13, no. 10, pp. 1882-1897, 2012.

[23] H. Wu, L. Liu, M. Lin et al., "Importance of the residue 190 on bactericidal activity of the bactericidal/permeability-increasing protein 5," Oncotarget, vol. 7, no. 28, pp. 43088-43094, 2016.

[24] T. Schuerholz, K. Brandenburg, and G. Marx, "Antimicrobial peptides and their potential application in inflammation and sepsis," Critical Care, vol. 16, no. 2, article 207, 2012.
[25] C. B. Park, K.-S. Yi, K. Matsuzaki, M. S. Kim, and S. C. Kim, "Structure-activity analysis of buforin II, a histone H2A-derived antimicrobial peptide: the proline hinge is responsible for the cell-penetrating ability of buforin II," Proceedings of the National Academy of Sciences of the United States of America, vol. 97, no. 15, pp. 8245-8250, 2000.

[26] J. A. Nash, T. N. S. Ballard, T. E. Weaver, and H. T. Akinbi, “The peptidoglycan-degrading property of lysozyme is not required for bactericidal activity in vivo," The Journal of Immunology, vol. 177, no. 1, pp. 519-526, 2006.

[27] D. A. C. Stapels, B. V. Geisbrecht, and S. H. M. Rooijakkers, "Neutrophil serine proteases in antibacterial defense," Current Opinion in Microbiology, vol. 23, pp. 42-28, 2015.

[28] I. Ginsburg, "The role of bacteriolysis in the pathophysiology of inflammation, infection and post-infectious sequelae," APMIS, vol. 110, no. 11, pp. 753-770, 2002.

[29] B. Korkmaz, M. S. Horwitz, D. E. Jenne, and F. Gauthier, "Neutrophil elastase, proteinase 3, and cathepsin G as therapeutic targets in human diseases," Pharmacological Reviews, vol. 62, no. 4, pp. 726-759, 2010.

[30] P. Kasperkiewicz, M. Poreba, S. J. Snipas et al., "Design of a selective substrate and activity based probe for human neutrophil serine protease 4," PLOS ONE, vol. 10, no. 7, Article ID e0132818, 2015.

[31] N. C. Perera, O. Schilling, H. Kittel, W. Back, E. Kremmer, and D. E. Jenne, "NSP4, an elastase-related protease in human neutrophils with arginine specificity," Proceedings of the National Academy of Sciences of the United States of America, vol. 109, no. 16, pp. 6229-6234, 2012.

[32] N. C. Perera, K.-H. Wiesmüller, M. T. Larsen et al., "NSP4 is stored in azurophil granules and released by activated neutrophils as active endoprotease with restricted specificity," Journal of Immunology, vol. 191, no. 5, pp. 2700-2707, 2013.

[33] W. Watorek, "Azurocidin-inactive serine proteinase homolog acting as a multifunctional inflammatory mediator," Acta Biochimica Polonica, vol. 50, no. 3, pp. 743-752, 2003.

[34] D. Legrand, "Overview of lactoferrin as a natural immune modulator," Journal of Pediatrics, vol. 173, supplement, pp. S10S15, 2016.

[35] S. Farnaud and R. W. Evans, "Lactoferrin-a multifunctional protein with antimicrobial properties," Molecular Immunology, vol. 40, no. 7, pp. 395-405, 2003.

[36] D. Caccavo, N. M. Pellegrino, M. Altamura et al., "Antimicrobial and immunoregulatory functions of lactoferrin and its potential therapeutic application," Journal of Endotoxin Research, vol. 8, no. 6, pp. 403-417, 2002.

[37] K. Okubo, M. Kamiya, Y. Urano et al., "Lactoferrin suppresses neutrophil extracellular traps release in inflammation," EBioMedicine, vol. 10, pp. 204-215, 2016.

[38] T. E. Kehl-Fie, S. Chitayat, M. I. Hood et al., "Nutrient metal sequestration by calprotectin inhibits bacterial superoxide defense, enhancing neutrophil killing of Staphylococcus aureus," Cell Host and Microbe, vol. 10, no. 2, pp. 158-164, 2011.

[39] R. D'Incà, E. Pont, V. Leo et al., "Calprotectin and lactoferrin in the assessment of intestinal inflammation and organic disease," International Journal of Colorectal Disease, vol. 22, no. 4, pp. 429-437, 2007.

[40] K. Daigo, N. Yamaguchi, T. Kawamura et al., "The proteomic profile of circulating pentraxin 3 (PTX3) complex in sepsis demonstrates the interaction with azurocidin 1 and other components of neutrophil extracellular traps," Molecular \& Cellular Proteomics, vol. 11, no. 6, 2012. 
[41] A. P. Levine and A. W. Segal, "The NADPH oxidase and microbial killing by neutrophils, with a particular emphasis on the proposed antimicrobial role of myeloperoxidase within the phagocytic vacuole," Microbiology Spectrum, vol. 4, no. 4, 2016.

[42] W. Theeß, J. Sellau, C. Steeg et al., "Myeloperoxidase attenuates pathogen clearance during Plasmodium yoelii nonlethal infection," Infection and Immunity, vol. 85, no. 1, Article ID e00475$16,2016$.

[43] S. J. Klebanoff, A. J. Kettle, H. Rosen, C. C. Winterbourn, and W. M. Nauseef, "Myeloperoxidase: a front-line defender against phagocytosed microorganisms," Journal of Leukocyte Biology, vol. 93, no. 2, pp. 185-198, 2013.

[44] A. Carestia, T. Kaufman, and M. Schattner, "Platelets: new bricks in the building of neutrophil extracellular traps," Frontiers in Immunology, vol. 7, article 271, 2016.

[45] K. M. Schmidt-Ott, K. Mori, Y. L. Jau et al., "Dual action of neutrophil gelatinase-associated lipocalin," Journal of the American Society of Nephrology, vol. 18, no. 2, pp. 407-413, 2007.

[46] S. Chakraborty, S. Kaur, S. Guha, and S. K. Batra, "The multifaceted roles of neutrophil gelatinase associated lipocalin (NGAL) in inflammation and cancer," Biochimica et Biophysica Acta-Reviews on Cancer, vol. 1826, no. 1, pp. 129-169, 2012.

[47] J. Bestebroer, M. J. J. G. Poppelier, L. H. Ulfman et al., "Staphylococcal superantigen-like 5 binds PSGL-1 and inhibits P-selectin-mediated neutrophil rolling," Blood, vol. 109, no. 7, pp. 2936-2943, 2007.

[48] J. Bestebroer, K. P. M. Van Kessel, H. Azouagh et al., "Staphylococcal SSL 5 inhibits leukocyte activation by chemokines and anaphylatoxins," Blood, vol. 113, no. 2, pp. 328-337, 2009.

[49] C. Fevre, J. Bestebroer, M. M. Mebius et al., "Staphylococcus aureus proteins SSL6 and SEIX interact with neutrophil receptors as identified using secretome phage display," Cellular Microbiology, vol. 16, no. 11, pp. 1646-1665, 2014.

[50] M. C. Chung, B. D. Wines, H. Baker, R. J. Langley, E. N. Baker, and J. D. Fraser, "The crystal structure of staphylococcal superantigen-like protein 11 in complex with sialyl Lewis X reveals the mechanism for cell binding and immune inhibition," Molecular Microbiology, vol. 66, no. 6, pp. 1342-1355, 2007.

[51] B. W. Bardoel, R. Vos, T. Bouman et al., "Evasion of Tolllike receptor 2 activation by staphylococcal superantigen-like protein 3," Journal of Molecular Medicine, vol. 90, no. 10, pp. 1109-1120, 2012.

[52] K. J. Koymans, L. J. Feitsma, T. H. C. Brondijk et al., "Structural basis for inhibition of TLR2 by staphylococcal superantigenlike protein 3 (SSL3)," Proceedings of the National Academy of Sciences of the United States of America, vol. 112, no. 35, pp. 1101811023, 2015.

[53] A. J. Laarman, G. Mijnheer, J. M. Mootz et al., "Staphylococcus aureus Staphopain A inhibits CXCR2-dependent neutrophil activation and chemotaxis," EMBO Journal, vol. 31, no. 17, pp. 3607-3619, 2012.

[54] P.-J. Haas, C. J. C. De Haas, W. Kleibeuker et al., "N-terminal residues of the chemotaxis inhibitory protein of Staphylococcus aureus are essential for blocking formylated peptide receptor but not C5a receptor," Journal of Immunology, vol. 173, no. 9, pp. 5704-5711, 2004.

[55] P.-J. Haas, C. J. C. De Haas, M. J. J. C. Poppelier et al., "The structure of the C5a receptor-blocking domain of chemotaxis inhibitory protein of Staphylococcus aureus is related to a group of immune evasive molecules," Journal of Molecular Biology, vol. 353, no. 4, pp. 859-872, 2005.
[56] D. Kretschmer, A.-K. Gleske, M. Rautenberg et al., "Human formyl peptide receptor 2 senses highly pathogenic Staphylococcus aureus," Cell Host and Microbe, vol. 7, no. 6, pp. 463-473, 2010.

[57] S. D. Kobayashi, K. R. Braughton, A. M. Palazzolo-Ballance et al., "Rapid neutrophil destruction following phagocytosis of Staphylococcus aureus," Journal of Innate Immunity, vol. 2, no. 6, pp. 560-575, 2010.

[58] R. Wang, K. R. Braughton, D. Kretschmer et al., "Identification of novel cytolytic peptides as key virulence determinants for community-associated MRSA," Nature Medicine, vol. 13, no. 12, pp. 1510-1514, 2007.

[59] T. Chavakis, M. Hussain, S. M. Kanse et al., "Staphylococcus aureus extracellular adherence protein serves as antiinflammatory factor by inhibiting the recruitment of host leukocytes," Nature Medicine, vol. 8, no. 7, pp. 687-693, 2002.

[60] A. J. Laarman, M. Ruyken, C. L. Malone, J. A. G. van Strijp, A. R. Horswill, and S. H. M. Rooijakkers, "Staphylococcus aureus metalloprotease aureolysin cleaves complement C3 to mediate immune evasion," The Journal of Immunology, vol. 186, no. 11, pp. 6445-6453, 2011.

[61] S. H. M. Rooijakkers, M. Ruyken, A. Roos et al., "Immune evasion by a staphylococcal complement inhibitor that acts on C3 convertases," Nature Immunology, vol. 6, no. 9, pp. 920-927, 2005.

[62] S. H. M. Rooijakkers, J. Wu, M. Ruyken et al., "Structural and functional implications of the alternative complement pathway C3 convertase stabilized by a staphylococcal inhibitor," Nature Immunology, vol. 10, no. 7, pp. 721-727, 2009.

[63] L. Y. L. Lee, M. Höök, D. Haviland et al., "Inhibition of complement activation by a secreted Staphylococcus aureus protein," Journal of Infectious Diseases, vol. 190, no. 3, pp. 571579, 2004.

[64] I. Jongerius, B. L. Garcia, B. V. Geisbrecht, J. A. G. Van Strijp, and S. H. M. Rooijakkers, "Convertase inhibitory properties of staphylococcal extracellular complement-binding protein," Journal of Biological Chemistry, vol. 285, no. 20, pp. 14973-14979, 2010.

[65] J. Bestebroer, P. C. Aerts, S. H. M. Rooijakkers et al., "Functional basis for complement evasion by staphylococcal superantigenlike 7," Cellular Microbiology, vol. 12, no. 10, pp. 1506-1516, 2010.

[66] A. M. E. Walenkamp, I. G. J. Boer, J. Bestebroer et al., "Staphylococcal superantigen-like 10 inhibits CXCL12-induced human tumor cell migration," Neoplasia, vol. 11, no. 4, pp. 333344, 2009.

[67] S. H. M. Rooijakkers, W. J. B. Van Wamel, M. Ruyken, K. P. M. Van Kessel, and J. A. G. Van Strijp, "Anti-opsonic properties of staphylokinase," Microbes and Infection, vol. 7, no. 3, pp. 476484, 2005.

[68] K. Haupt, M. Reuter, J. van den Elsen et al., “The Staphylococcus aureus protein Sbi acts as a complement inhibitor and forms a tripartite complex with host complement Factor H and C3b," PLoS Pathogens, vol. 4, no. 12, Article ID e1000250, 2008.

[69] J. D. Burman, E. Leung, K. L. Atkins et al., "Interaction of human complement with Sbi, a staphylococcal immunoglobulinbinding protein: indications of a novel mechanism of complement evasion by Staphylococcus aureus," The Journal of Biological Chemistry, vol. 283, no. 25, pp. 17579-17593, 2008.

[70] H. K. Kim, A. G. Cheng, H.-Y. Kim, D. M. Missiakas, and O. Schneewind, "Nontoxigenic protein A vaccine for methicillinresistant staphylococcus aureus infections in mice," Journal of Experimental Medicine, vol. 207, no. 9, pp. 1863-1870, 2010. 
[71] N. Malachowa, P. L. Kohler, P. M. Schlievert et al., "Characterization of a staphylococcus aureus surface virulence factor that promotes resistance to oxidative killing and infectious endocarditis," Infection and Immunity, vol. 79, no. 1, pp. 342352, 2011.

[72] J. S. Nanra, S. M. Buitrago, S. Crawford et al., "Capsular polysaccharides are an important immune evasion mechanism for Staphylococcus aureus," Human Vaccines and Immunotherapeutics, vol. 9, no. 3, pp. 480-487, 2013.

[73] J. A. Sharp, C. G. Echague, P. S. Hair et al., "Staphylococcus aureus surface protein $\mathrm{SdrE}$ binds complement regulator factor $\mathrm{H}$ as an immune evasion tactic," PLoS ONE, vol. 7, no. 5, Article ID e38407, 2012.

[74] L. Visai, N. Yanagisawa, E. Josefsson et al., "Immune evasion by Staphylococcus aureus conferred by iron-regulated surface determinant protein IsdH," Microbiology, vol. 155, no. 3, pp. 667-679, 2009.

[75] Y. Zong, Y. Xu, X. Liang et al., "A 'Collagen Hug' model for Staphylococcus aureus CNA binding to collagen," The EMBO Journal, vol. 24, no. 24, pp. 4224-4236, 2005.

[76] A. L. DuMont, P. Yoong, B. G. J. Surewaard et al., "Staphylococcus aureus elaborates leukocidin $\mathrm{AB}$ to mediate escape from within human neutrophils," Infection and Immunity, vol. 81, no. 5, pp. 1830-1841, 2013.

[77] F. Alonzo III, L. Kozhaya, S. A. Rawlings et al., "CCR5 is a receptor for Staphylococcus aureus leukotoxin ED," Nature, vol. 493, no. 7430, pp. 51-55, 2013.

[78] C. L. Ventura, N. Malachowa, C. H. Hammer et al., "Identification of a novel Staphylococcus aureus two-component leukotoxin using cell surface proteomics," PLOS ONE, vol. 5, no. 7, Article ID e11634, 2010.

[79] A. N. Spaan, T. Henry, W. J. M. Van Rooijen et al., “The staphylococcal toxin panton-valentine leukocidin targets human C5a receptors," Cell Host and Microbe, vol. 13, no. 5, pp. 584-594, 2013.

[80] I. Inoshima, N. Inoshima, G. A. Wilke et al., "A Staphylococcus aureus pore-forming toxin subverts the activity of ADAM10 to cause lethal infection in mice," Nature Medicine, vol. 17, no. 10, pp. 1310-1314, 2011.

[81] A. Clauditz, A. Resch, K.-P. Wieland, A. Peschel, and F. Götz, "Staphyloxanthin plays a role in the fitness of Staphylococcus aureus and its ability to cope with oxidative stress," Infection and Immunity, vol. 74, no. 8, pp. 4950-4953, 2006.

[82] K. Cosgrove, G. Coutts, I.-M. Jonsson et al., "Catalase (KatA) and alkyl hydroperoxide reductase (AhpC) have compensatory roles in peroxide stress resistance and are required for survival, persistence, and nasal colonization in Staphylococcus aureus," Journal of Bacteriology, vol. 189, no. 3, pp. 1025-1035, 2007.

[83] Y. Y. Pang, J. Schwartz, S. Bloomberg, J. M. Boyd, A. R. Horswill, and W. M. Nauseef, "Methionine sulfoxide reductases protect against oxidative stress in staphylococcus aureus encountering exogenous oxidants and human neutrophils," Journal of Innate Immunity, vol. 6, no. 3, pp. 353-364, 2014.

[84] V. Thammavongsa, O. Schneewind, and D. M. Missiakas, "Enzymatic properties of Staphylococcus aureus adenosine synthase (AdsA)," BMC Biochemistry, vol. 12, no. 1, article 56, 2011.

[85] J. E. Cassat and E. P. Skaar, "Metal ion acquisition in Staphylococcus aureus: overcoming nutritional immunity, Seminars in Immunopathology, vol. 34, no. 2, pp. 215-235, 2012.

[86] A. Bera, S. Herbert, A. Jakob, W. Vollmer, and F. Götz, "Why are pathogenic staphylococci so lysozyme resistant? The peptidoglycan $\mathrm{O}$-acetyltransferase OatA is the major determinant for lysozyme resistance of Staphylococcus aureus," Molecular Microbiology, vol. 55, no. 3, pp. 778-787, 2005.

[87] S. Herbert, A. Bera, C. Nerz et al., "Molecular basis of resistance to muramidase and cationic antimicrobial peptide activity of lysozyme in staphylococci," PLoS Pathogens, vol. 3, no. 7, p. e102, 2007.

[88] D. A. C. Stapels, K. X. Ramyar, M. Bischoff et al., "Staphylococcus aureus secretes a unique class of neutrophil serine protease inhibitors," Proceedings of the National Academy of Sciences of the United States of America, vol. 111, no. 36, pp. 13187-13192, 2014.

[89] E. T. M. Berends, A. R. Horswill, N. M. Haste, M. Monestier, V. Nizet, and M. Von Köckritz-Blickwede, "Nuclease expression by Staphylococcus aureus facilitates escape from neutrophil extracellular traps," Journal of Innate Immunity, vol. 2, no. 6, pp. 576-586, 2010.

[90] A. Schreiber, C. T. N. Pham, Y. Hu, W. Schneider, F. C. Luft, and R. Kettritz, "Neutrophil serine proteases promote IL-1 $\beta$ generation and injury in necrotizing crescentic glomerulonephritis," Journal of the American Society of Nephrology, vol. 23, no. 3, pp. 470-482, 2012.

[91] G. Canny and O. Levy, "Bactericidal/permeability-increasing protein (BPI) and BPI homologs at mucosal sites," Trends in Immunology, vol. 29, no. 11, pp. 541-547, 2008.

[92] B. D. Corbin, E. H. Seeley, A. Raab et al., "Metal chelation and inhibition of bacterial growth in tissue abscesses," Science, vol. 319, no. 5865, pp. 962-965, 2008.

[93] N. D. Embleton, J. E. Berrington, W. McGuire, C. J. Stewart, and S. P. Cummings, "Lactoferrin: antimicrobial activity and therapeutic potential," Seminars in Fetal and Neonatal Medicine, vol. 18, no. 3, pp. 143-149, 2013.

[94] S. Mayeur, S. Spahis, Y. Pouliot, and E. Levy, "Lactoferrin, a pleiotropic protein in health and disease," Antioxidants \& Redox Signaling, vol. 24, no. 14, pp. 813-836, 2016.

[95] J. H. Brock, "Lactoferrin-50 years on," Biochemistry and Cell Biology, vol. 90, no. 3, pp. 245-251, 2012.

[96] V. Brinkmann, U. Reichard, C. Goosmann et al., "Neutrophil extracellular traps kill bacteria," Science, vol. 303, no. 5663, pp. 1532-1535, 2004

[97] J. Bestebroer, K. P. van Kessel, H. Azouagh et al., "Staphylococcal SSL5 inhibits leukocyte activation by chemokines and anaphylatoxins," Blood, vol. 113, no. 2, pp. 328-337, 2009.

[98] B. McDonald, R. Urrutia, B. G. Yipp, C. N. Jenne, and P. Kubes, "Intravascular neutrophil extracellular traps capture bacteria from the bloodstream during sepsis," Cell Host \& Microbe, vol. 12, no. 3, pp. 324-333, 2012.

[99] C. G. Baums and M. von Köckritz-Blickwede, "Novel role of DNA in neutrophil extracellular traps," Trends in Microbiology, vol. 23, no. 6, pp. 330-331, 2015.

[100] T. A. Fuchs, U. Abed, C. Goosmann et al., "Novel cell death program leads to neutrophil extracellular traps," Journal of Cell Biology, vol. 176, no. 2, pp. 231-241, 2007.

[101] H. Yang, M. H. Biermann, J. M. Brauner, Y. Liu, Y. Zhao, and M. Herrmann, "New insights into neutrophil extracellular traps: mechanisms of formation and role in inflammation," Frontiers in Immunology, vol. 7, article 302, 2016.

[102] B. Amulic and G. Hayes, "Neutrophil extracellular traps," Current Biology, vol. 21, no. 9, pp. R297-R298, 2011.

[103] V. Thammavongsa, H. K. Kim, D. Missiakas, and O. Schneewind, "Staphylococcal manipulation of host immune responses," Nature Reviews Microbiology, vol. 13, no. 9, pp. 529-543, 2015. 
[104] K. Ley, C. Laudanna, M. I. Cybulsky, and S. Nourshargh, "Getting to the site of inflammation: the leukocyte adhesion cascade updated," Nature Reviews Immunology, vol. 7, no. 9, pp. 678-689, 2007.

[105] B. Postma, M. J. Poppelier, J. C. Van Galen et al., "Chemotaxis inhibitory protein of Staphylococcus aureus binds specifically to the C5a and formylated peptide receptor," Journal of Immunology, vol. 172, no. 11, pp. 6994-7001, 2004.

[106] W. J. B. Van Wamel, S. H. M. Rooijakkers, M. Ruyken, K. P. M. Van Kessel, and J. A. G. Van Strijp, "The innate immune modulators staphylococcal complement inhibitor and chemotaxis inhibitory protein of Staphylococcus aureus are located on $\beta$ hemolysin-converting bacteriophages," Journal of Bacteriology, vol. 188, no. 4, pp. 1310-1315, 2006.

[107] B. W. Bardoel, E. F. Kenny, G. Sollberger, and A. Zychlinsky, "The balancing act of neutrophils," Cell Host and Microbe, vol. 15, no. 5, pp. 526-536, 2014.

[108] W. McGuinness, S. Kobayashi, and F. DeLeo, "Evasion of neutrophil killing by Staphylococcus aureus," Pathogens, vol. 5, no. 1, p. 32, 2016

[109] S. H. M. Rooijakkers and J. A. G. van Strijp, "Bacterial complement evasion," Molecular Immunology, vol. 44, no. 1-3, pp. 23-32, 2007.

[110] J. D. Burman, E. Leung, K. L. Atkins et al., "Interaction of human complement with Sbi, a staphylococcal immunoglobulinbinding protein: indications of a novel mechanism of complement evasion by Staphylococcus aureus," Journal of Biological Chemistry, vol. 283, no. 25, pp. 17579-17593, 2008.

[111] E. J. Smith, R. M. Corrigan, T. van der Sluis et al., "The immune evasion protein Sbi of Staphylococcus aureus occurs both extracellularly and anchored to the cell envelope by binding lipoteichoic acid," Molecular Microbiology, vol. 83, no. 4, pp. 789-804, 2012.

[112] E. J. Smith, L. Visai, S. W. Kerrigan, P. Speziale, and T. J. Foster, "The Sbi protein is a multifunctional immune evasion factor of Staphylococcus aureus," Infection and Immunity, vol. 79, no. 9, pp. 3801-3809, 2011.

[113] Y.-P. Ko, A. Kuipers, C. M. Freitag et al., "Phagocytosis escape by a Staphylococcus aureus protein that connects complement and coagulation proteins at the bacterial surface," PLOS Pathogens, vol. 9, no. 12, Article ID e1003816, 2013.

[114] P. S. Hair, C. G. Echague, A. M. Sholl et al., "Clumping factor A interaction with complement factor I increases C3b cleavage on the bacterial surface of Staphylococcus aureus and decreases complement-mediated phagocytosis," Infection and Immunity, vol. 78, no. 4, pp. 1717-1727, 2010.

[115] P. S. Hair, M. D. Ward, O. J. Semmes, T. J. Foster, and K. M. Cunnion, "Staphylococcus aureus clumping factor A binds to complement regulator factor I and increases factor I cleavage of C3b," The Journal of Infectious Diseases, vol. 198, no. 1, pp. 125$133,2008$.

[116] J. Higgins, A. Loughman, K. P. M. Van Kessel, J. A. G. Van Strijp, and T. J. Foster, "Clumping factor A of Staphylococcus aureus inhibits phagocytosis by human polymorphonuclear leucocytes," FEMS Microbiology Letters, vol. 258, no. 2, pp. 290296, 2006.

[117] T. J. Foster, J. A. Geoghegan, V. K. Ganesh, and M. Höök, "Adhesion, invasion and evasion: the many functions of the surface proteins of Staphylococcus aureus," Nature Reviews Microbiology, vol. 12, no. 1, pp. 49-62, 2014.
[118] F. E. Guerra, C. B. Addison, N. W. de Jong et al., "Staphylococcus aureus SaeR/S-regulated factors reduce human neutrophil reactive oxygen species production," Journal of Leukocyte Biology, vol. 100, no. 5, pp. 1005-1010, 2016.

[119] V. Thammavongsa, J. W. Kern, D. M. Missiakas, and O. Schneewind, "Staphylococcus aureus synthesizes adenosine to escape host immune responses," The Journal of Experimental Medicine, vol. 206, no. 11, pp. 2417-2427, 2009.

[120] B. N. Cronstein, L. Daguma, D. Nichols, A. J. Hutchison, and M. Williams, "The adenosine/neutrophil paradox resolved: human neutrophils possess both $\mathrm{A} 1$ and $\mathrm{A} 2$ receptors that promote chemotaxis and inhibit O-2 generation, respectively," Journal of Clinical Investigation, vol. 85, no. 4, pp. 1150-1157, 1990.

[121] D. Legrand, "Overview of lactoferrin as a natural immune modulator," The Journal of Pediatrics, vol. 173, pp. S10-S15, 2016.

[122] S. R. Clarke and S. J. Foster, "IsdA protects Staphylococcus aureus against the bactericidal protease activity of apolactoferrin," Infection and Immunity, vol. 76, no. 4, pp. 1518-1526, 2008.

[123] A. Mayer-Scholl, P. Averhoff, and A. Zychlinsky, "How do neutrophils and pathogens interact?" Current Opinion in Microbiology, vol. 7, no. 1, pp. 62-66, 2004.

[124] A. do Vale, D. Cabanes, and S. Sousa, "Bacterial toxins as pathogen weapons against phagocytes," Frontiers in Microbiology, vol. 7, article 42, 2016.

[125] A. Peschel and M. Otto, "Phenol-soluble modulins and staphylococcal infection," Nature Reviews Microbiology, vol. 11, no. 10, pp. 667-673, 2013.

[126] B. G. J. Surewaard, C. J. C. De Haas, F. Vervoort et al., "Staphylococcal alpha-phenol soluble modulins contribute to neutrophil lysis after phagocytosis," Cellular Microbiology, vol. 15, no. 8, pp. 1427-1437, 2013.

[127] M. Otto, "Phenol-soluble modulins," International Journal of Medical Microbiology, vol. 304, no. 2, pp. 164-169, 2014.

[128] A.-L. Genestier, M.-C. Michallet, G. Prévost et al., "Staphylococcus aureus Panton-Valentine leukocidin directly targets mitochondria and induces Bax-independent apoptosis of human neutrophils," Journal of Clinical Investigation, vol. 115, no. 11, pp. 3117-3127, 2005.

[129] B. Löffler, M. Hussain, M. Grundmeier et al., "Staphylococcus aureus panton-valentine leukocidin is a very potent cytotoxic factor for human neutrophils," PLoS Pathogens, vol. 6, no. 1, Article ID e1000715, 2010.

[130] B. K. Dhakal and M. A. Mulvey, "The UPEC pore-forming toxin $\alpha$-hemolysin triggers proteolysis of host proteins to disrupt cell adhesion, inflammatory, and survival pathways," Cell Host and Microbe, vol. 11, no. 1, pp. 58-69, 2012.

[131] B. J. Berube and J. B. Wardenburg, "Staphylococcus aureus $\alpha$ toxin: nearly a century of intrigue," Toxins, vol. 5, no. 6, pp. 11401166, 2013.

[132] A. H. Bartlett, T. J. Foster, A. Hayashida, and P. W. Park, “ $\alpha$ toxin facilitates the generation of CXC chemokine gradients and stimulates neutrophil homing in Staphylococcus aureus pneumonia," Journal of Infectious Diseases, vol. 198, no. 10, pp. 1529-1535, 2008.

[133] V. Thammavongsa, D. M. Missiakas, and O. Schneewind, "Staphylococcus aureus degrades neutrophil extracellular traps to promote immune cell death," Science, vol. 342, no. 6160, pp. 863-866, 2013.

[134] A. N. Spaan, B. G. J. Surewaard, R. Nijland, and J. A. G. van Strijp, "Neutrophils versus Staphylococcus aureus: a biological tug of war," Annual Review of Microbiology, vol. 67, no. 1, pp. 629-650, 2013. 
[135] R. Corriden, A. Hollands, J. Olson et al., “Tamoxifen augments the innate immune function of neutrophils through modulation of intracellular ceramide," Nature Communications, vol. 6, article no. 8369, 2015.

[136] A. Hollands, R. Corriden, G. Gysler et al., "Natural product anacardic acid from cashew nut shells stimulates neutrophil extracellular trap production and bactericidal activity," The Journal of Biological Chemistry, vol. 291, no. 27, pp. 13964-13973, 2016. 


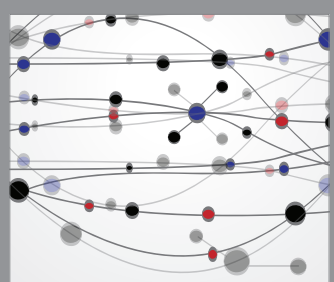

The Scientific World Journal
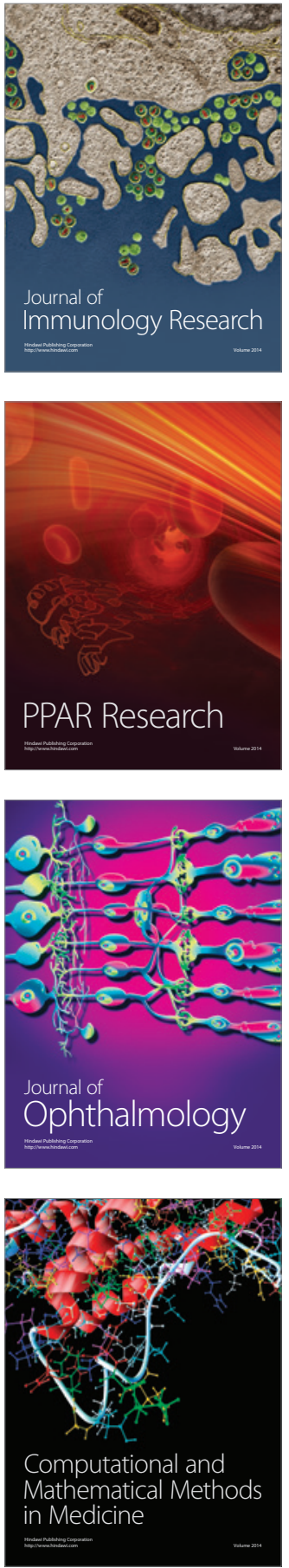

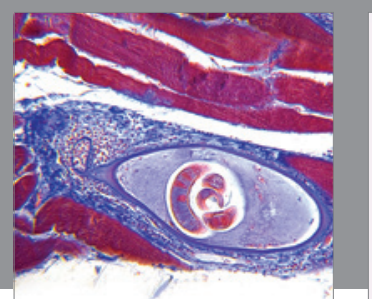

Gastroenterology Research and Practice
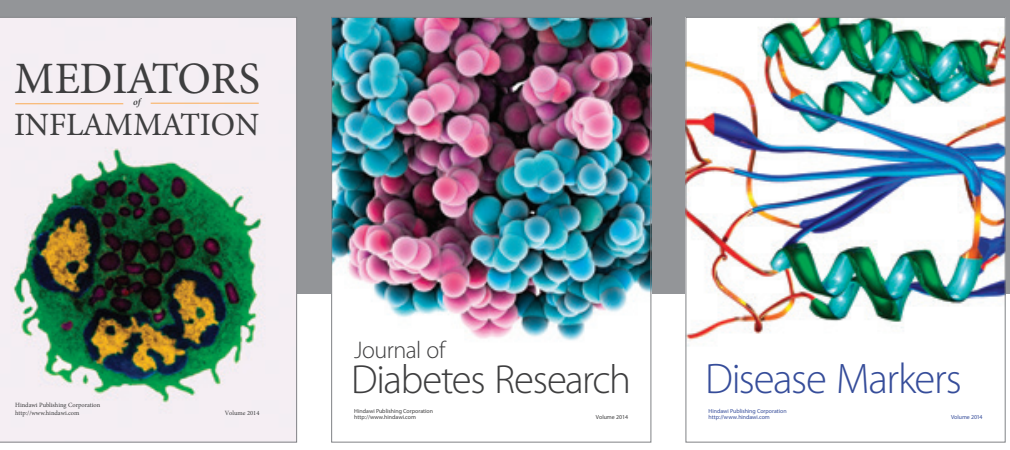

Disease Markers

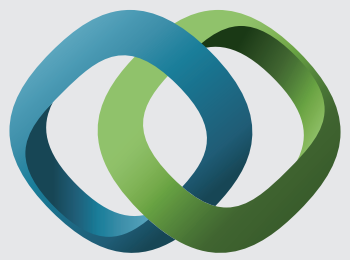

\section{Hindawi}

Submit your manuscripts at

https://www.hindawi.com
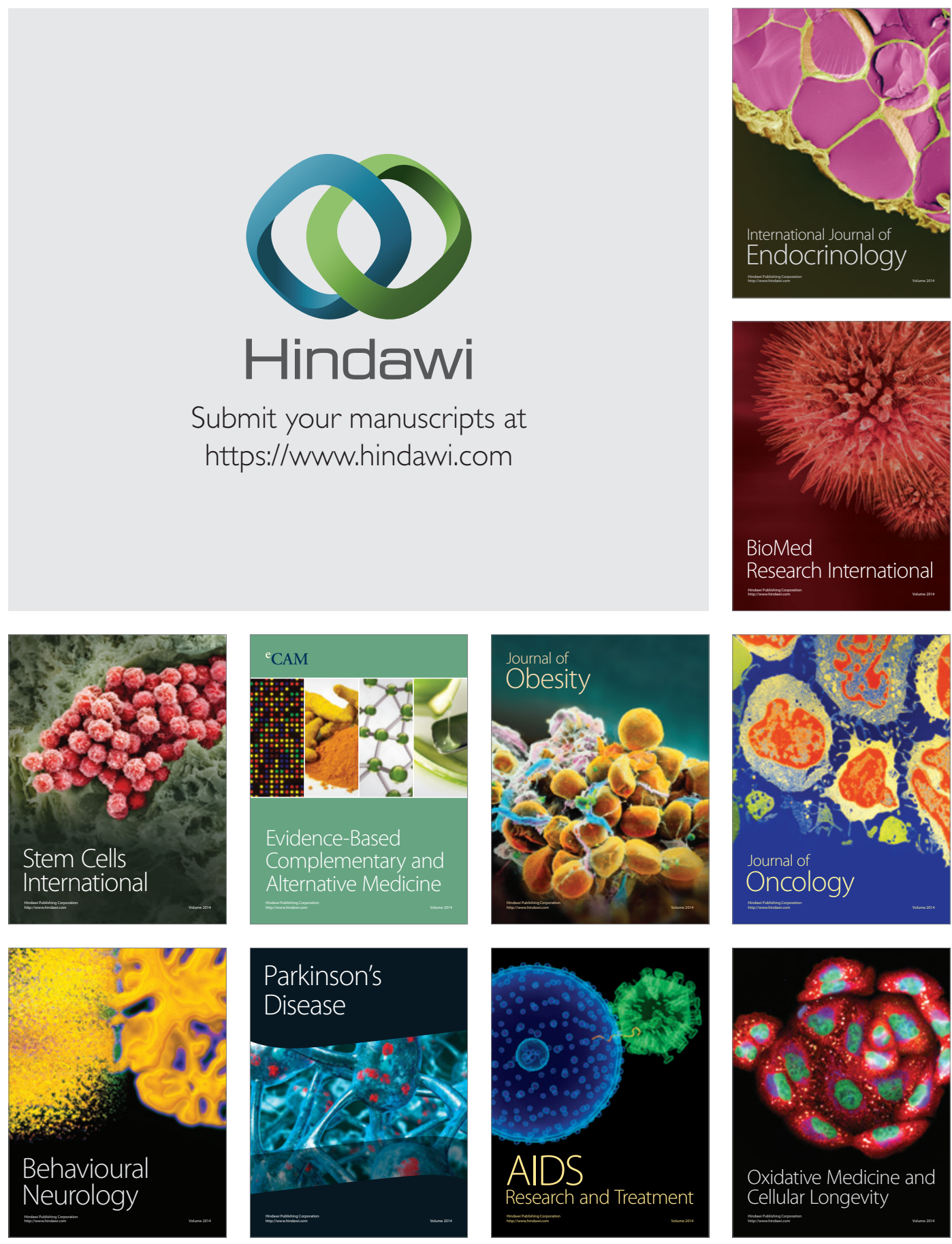